\title{
Zinc improves the immune function and the proliferation of lymphocytes in Cadmium-treated rats
}

\author{
HOSSAM EBAID ${ }^{1,2}$, IFTEKHAR HASSAN ${ }^{l}$, SAMIR BASHANDY $Y^{3}$ NAEL ABU TAHA ${ }^{l}$, \\ AMER MAHMOOD ${ }^{4}$, SULIMAN ALOMAR ${ }^{l}$, IBRAHIM ALHAZZA ${ }^{l}$, ASHRAF MASHALY ${ }^{1,2}$, \\ AHMED RADY
}

'Department of Zoology, College of Science, King Saud University, Kingdom of Saudi Arabia

${ }^{2}$ Department of Zoology, Faculty of Science, El-Minia University, Egypt

${ }^{3}$ Department of Pharmacology, National Research Center, Cairo, Egypt

${ }^{4}$ Department of Anatomy, College of Medicine, King Saud University, Kingdom of Saudi Arabia

\begin{abstract}
The effects of Cadmium (Cd) exposure and the treatment with Zinc (Zn) on immune functions of splenocytes and cultured lymphocytes of rats were studied. The exposure of rats to $C d$ was at a dose of $2.2 \mathrm{mg} / \mathrm{kg} \mathrm{CdCl}$, injected subcutaneously four times weekly for 2 months. Rats were supplemented with $\mathrm{Zn}(2.2 \mathrm{mg} / \mathrm{kg} \mathrm{ZnCl}$, injected subcutaneously four times weekly for 2 months) one hour prior to $C d$ exposure. Spleens were removed and splenocytes were isolated and cultured. The proliferation capacity of lymphocytes and their homing to the spleen were studied. Ribonucleic acid (RNA) was extracted from stimulated lymphocytes in order to analyse gene expressions using RT-PCR. Accordingly, proliferation of lymphocytes was found to be suppressed in $C d$-treated rats, both in vivo and in vitro. Zinc served to activate the proliferation of $B$ and T lymphocytes in $C d$-treated rats both in vivo and in vitro. Antigen-activated lymphocytes showed that Cd impaired the mRNA expression of CD68, Ccl22 and CXCL10. Zinc was not found to restore mRNA expression of these genes to the normal levels. Zinc was found to decrease the MDA level with replenishment of activity of key antioxidant enzymes and proteins in Cd-pre-treated animals significantly. Moreover, the histopathological examination of spleen samples also agreed with the molecular, immunological and redox findings. Hence, $\mathrm{Zn}$ is able to restore the normal structure, redox status and immunity in Cd-induced damage in the rat model system.
\end{abstract}

Key words: Cadmium, Zinc, oxidative stress, lymphocyte subsets, chemokines.

(Centr Eur J Immunol 2014; 39 (4): 441-448)

\section{Introduction}

Cadmium (Cd) is one of the most prevalent environmental and biologically hazardous toxicants among metals. With no any reported significance in the biological system; it has been documented as a major pollutant in environment and biological systems [1, 2]. It gets into our body through occupational exposure by inhaling fine dust and fume in industries of cement, petroleum, fertilizers, mining, steel and iron and even at the hospital and municipal solid waste incineration plants [3]. It is also used as a food adulterant to increase the look, flavor and shelf life of many food items and beverages like soft drinks, fruit juice, bread, root crops, and vegetables. It is also found in cigarette smoke, rechargeable batteries and certain types of cosmetics. The presence of $\mathrm{Cd}$ over the permissible level has acute as well as chronic health hazards. It can cause various clinical problems including upper respiratory tract irritation, pulmonary edema, muscular dystrophy, osteoporosis, neurological disorders and even cancers depending on the dose and incubation [4-6]. So, with its prevalence in daily, general consuming products, a great deal of scientific research is focused on ameliorating the toxic of $\mathrm{Cd}$ around the world.

Zinc $(\mathrm{Zn})$ is one of the most important transition metals after iron in all forms of the biological system. It is supposedly imparted in over 100 enzymes assisting in metabolism, DNA-transcription, stress management, immunity, reproduction and nervous system [7]. It can act as a nutrient and antioxidant if taken in moderation while it acts as a pro-oxidant and even toxicant if taken in high dose [8]. It is required for the expression of important antioxidant molecules like superoxide dismutase and

Correspondence: Hossam Ebaid, Department of Zoology, College of Science, King Saud University, P.O. Box 2455, Riyadh - 11451, Kingdom of Saudi Arabia, e-mail: hossamebaid@yahoo.com 
metallothionein that maintains redox homeostasis in living organisms $[9,10]$. Besides, its excess as well as deficiency both have negative effects on the immune response exacerbating any infection or inflammation in animals and humans [7, 11].

No doubt that chemokines are involved in a wide variety of processes during pathological conditions [12] by directing the migration and positioning of inflammatory and immune cells within the tissue [13]. They can be secreted by and act on different cell types depending on the expression of specific receptors, and are known to be involved in leukocyte trafficking [14]. Recruited Th1 lymphocytes may enhance interferon $\gamma$ (IFN- $\gamma$ ) and tumor necrosis factor $\alpha$ (TNF- $\alpha$ ) production, which in turn stimulates CXCL10 secretion from a variety of cells [15]. CXCL10 is secreted by several cell types including CD4+, CD8+, NK and NK-T cells, endothelial cells, fibroblasts, keratinocytes, thyrocytes, preadipocytes, etc. [15]. Th2 lymphocytes expressing CCR4 are attracted by CCL22, while Th17 lymphocytes expressing CXCR3 and CCR6 are attracted to the liver by the secretion of CXCL9, CXCL10 and CXCL11 [13]. Recent studies have targeted the interaction between CCR4 expressed on Tregs and its ligands, CCL22, (macro-phage-derived chemokine) and CCL17 (actiwation-regulated chemokine), to inhibit transiently the recruitment of Tregs at the site of immunization [16].

The present study is aimed to address the toxicological threats posed by $\mathrm{Cd}$ with the help of supplementation of $\mathrm{Zn}$ in a rodent-based investigation.

\section{Material and methods}

\section{Chemicals}

Cadmium as Cadmium chloride $\left(\mathrm{CdCl}_{2}\right)$ and Zinc as Zinc chloride $\left(\mathrm{ZnCl}_{2}\right)$ were purchased from Merck (Darmstadt, Germany). All of the chemicals used in the present study were of the analytical purity.

\section{Experimental animals}

A total of 40 male rats (12-week-old), weighing 120$150 \mathrm{~g}$ each, were purchased from the Central Animal House of the Faculty of Pharmacy at King Saud University, Riyadh, KSA. All the animals were acclimatized in metal cages inside a well-ventilated room for 2 weeks prior to the treatment. They were maintained under standard laboratory conditions (temperature $23^{\circ} \mathrm{C}$, relative humidity 60-70\% and a 12-h light/dark cycle) and were fed a diet of standard commercial pellets and water ad libitum.

\section{Experimental design}

Animals were randomly distributed into four experimental groups ( $n=10 /$ group): group I served as the control group supplemented with $0.1 \mathrm{ml}$ of saline. Group II was administered $\mathrm{Cd}$ at a dose of $2.2 \mathrm{mg} / \mathrm{kg} \mathrm{CdCl}$ in $0.1 \mathrm{ml}$ of saline by subcutaneous injection four times weekly for
2 months. Rats of group III were injected with $\mathrm{Cd}$ in the same way as group II followed by supplementation with $\mathrm{Zn}(2.2 \mathrm{mg} / \mathrm{kg} \mathrm{ZnCl}$, injected subcutaneously four times weekly for 2 months) at the gap of one hour. Group IV was supplemented with $\mathrm{Zn}$ at a dose of $2.2 \mathrm{mg} / \mathrm{kg} \mathrm{ZnCl}{ }_{2}$ injected subcutaneously four times weekly for 2 months.

\section{Assay of antioxidant enzymes (SOD and CAT)}

The activity of different antioxidant enzymes were assayed with standard protocols. CuZn superoxide dismutase (CuZnSOD) was assayed by autoxidation of pyrogallol [17] while that of catalase (CAT) was done by decomposition of hydrogen peroxide [18].

\section{Estimation of the glutathione level}

The level of reduced glutathione (GSH) was estimated by the method of Jollow et al. [19].

\section{Estimation of the malondialdehyde level}

The extent of lipid peroxidation was estimated by the method of Buege and Aust [20] involving the measurement of total malondialdehyde (MDA).

\section{Histological sections}

Spleen parts were collected from the sacrificed control and different treated groups of rats. Tissues were fixed in Bouin's fixative, processed in paraffin followed by their sectioning of $4 \mu \mathrm{m}$ thickness. Moreover, sections were stained with Haematoxylin and Eosin (H\&E) for general histological architecture. In each group, many sections from different rats were investigated to distinguish the clear and common changes that were finally photographed. Sections from at least five rats were carefully investigated.

\section{Immunohistochemical detection of $\mathbf{T}$ and $B$ cells}

Spleen samples were fixed in $10 \%$ neutral buffered formalin. Paraffin sections were cleared in xylene, rehydrated in graded ethanol (100-70\%), immersed in water for 5 to 10 minutes, and incubated in $0.3 \% \mathrm{H}_{2} \mathrm{O}_{2}$ in $70 \%$ methanol for 20 minutes to inhibit endogenous peroxidase activity. The specimens were then rinsed three times for 5 minutes in PBS, and epitopes were unmasked by boiling in citrate buffer $(\mathrm{pH}$ 6.0) for 15 minutes whenever necessary. The sections were then blocked for 60 minutes in 3\% BSA, in 1\% normal goat serum and $3 \%$ non-fat milk. Sections were incubated with primary antibodies anti-CD3 (pan T cells or anti-CD20; pan $\mathrm{B}$ cells) in $0.1 \% \mathrm{BSA}$ overnight at $4^{\circ} \mathrm{C}$ in a humidified chamber. Samples were then rinsed in PBS and incubated with biotinylated secondary antibody in $0.1 \%$ BSA for 1 hour at room temperature, followed by avidin biotin amplification (ABC Elite) for 30 minutes. Sections were developed with 3,3-diaminobenzidine peroxidase substrate (Sigma). Sections 
were counterstained with Mayer haematoxylin for 3 minutes and mounted. Negative controls were set by substituting the primary antibody with PBS [21]. Photographs of the sections were taken; the images were digitized using Adobe Photoshop (Adobe Systems, Mountain View, CA). The PCNA (the number of brown stained cells), anti-CD3 or anti-CD20stained cells were determined at 20 random locations within the spleen follicles and the PALS for each animal from each group using a Leica Qwin 500 image analyzer.

\section{RNA extraction and RT-PCR}

RNA was extracted from the collected samples (RNA latter) using RNeasy Mini Kit (QIAGEN) according to the manufacturer's instructions. RT-PCR was performed using QIAGEN One Step RT-PCR kit as directed by the manufacturer's instruction manual. The desired genes were amplified using specific primers (e-oligos, Hawthorne, USA) listed in Table 1. For each sample, $25 \mu$ reaction mixture was performed. PCR reaction was carried out using Gene-Amp 9700 thermal cycler. RT-PCR products were analysed in $1.2 \%$ agarose gel. PCR conditions were optimized to allow semiquantitative comparisons of results, as previously described [22]. The levels of the three mRNA and $\beta$-actin mRNA were quantified by gel electrophoresis and densitometry. mRNA levels were normalized versus $\beta$-actin and are expressed in arbitrary units.

\section{Lymphocyte isolation}

Rats were anesthetized and euthanized; spleen was taken out immediately followed by their rinsing with cold phosphate buffered saline. Then, it was placed on a 200mesh stain steel sieve and grounded with plunger of the glass syringe. Two volumes of isolated lymphocyte separation medium were added, mixed gently and centrifuged at 2,000 $\times \mathrm{g}$ for $10 \mathrm{~min}$. The top layer was discharged leaving the middle lamella layer showing color of milk cream containing lymphocytes. Five volumes of PBS buffer were added and centrifuged at $1,000 \times \mathrm{g}$ for $5 \mathrm{~min}$. Precipitated lymphocytes were re-suspended in RPMI-1640 medium (making the final concentration of $1 \times 10^{6}$ cells $/ \mathrm{ml}$ ). The viability of lymphocytes was analyzed using trypan blue, and in all acceptable preparations, it exceeded $95 \%$.

\section{Statistical analysis}

All the data have been expressed as mean \pm standard error of mean (SEM) for 6 different preparations in duplicate. Their statistical significance was evaluated by oneway ANOVA and Tukey's post hoc analysis by 'GraphPad Prism 5'. The probability of occurrence was selected at $p \leq 0.05$. The treatment and the experiments were repeated twice to check reproducibility of the results.

\section{Results}

\section{Effect on the level of reduced glutathione}

Glutathione (GSH) is considered as one of the main indicators of oxidative stress in the biological system. So, its estimation was conducted in tissue homogenates of spleen to assess the burden of oxidative stress after their treatment with $\mathrm{Zn}, \mathrm{Cd}$ and their combination. The treatment of rats with $\mathrm{Zn}$ caused a decrease in its level by $8.4 \%$ in spleen samples while it was $40.4 \%$ in Cd-treated group spleen samples. Hitherto, a combination group with $\mathrm{Cd}$ and $\mathrm{Zn}$ treatment showed a healing effect of $\mathrm{Zn}$ on Cd-pre-treated rats demonstrating replenishment in the GSH level by $27.4 \%$ in spleen (Fig. 1A).

\section{Effect on antioxidant enzymes}

To assess the oxidative stress, activity of an important antioxidant enzyme, CAT, was assayed. After the treatment with $\mathrm{Zn}$, it showed a decrease in catalase activity by $15.4 \%$ in spleen samples as compared to the control while Cd exhibited $33.6 \%$ of decrease for the same. However, its activity was found to be recovered in the combination group $(\mathrm{Cd}+\mathrm{Zn})$ by $22.8 \%$ in spleen samples as compared to Cd-treated rats (Fig. 1B).

Superoxide dismutase (SOD) is considered as one of the primary antioxidant enzymes in living systems. Treatment of rats with $\mathrm{Zn}$ caused a mild decrease in its activity as evidenced by group IV but group II (Cd-treated rats) showed a marked decline in its activity by $31.3 \%$ in spleen samples. Intriguingly, treatment of $\mathrm{Zn}$ caused a significant recovery in its activity by $27.6 \%$ in spleen samples as compared to Cd-pre-treated rats (Fig. 1C).

Table 1. List of primers used to amplify the desired genes

\begin{tabular}{cllc}
\hline Primer name & & & Primer length \\
\hline \multirow{2}{*}{ CD68 } & Forward & GGACCCACAACTGTCACTCAT & 21 \\
\cline { 2 - 4 } & Reverse & AAGCCCCACTTTAGCTTTACC & 21 \\
\hline \multirow{2}{*}{ Ccl-22 } & Forward & AGGTCCCTATGGTGCCAATGT & 21 \\
\cline { 2 - 4 } & Reverse & CGGCAGGATTTTGAGGTCCA & 20 \\
\hline \multirow{2}{*}{ CXCL-10 } & Forward & CCAAGTGCTGCCGTCATTTTC & 21 \\
\cline { 2 - 4 } & Reverse & GGCTCGCAGGGATGATTTCAA & 21 \\
\hline
\end{tabular}


A

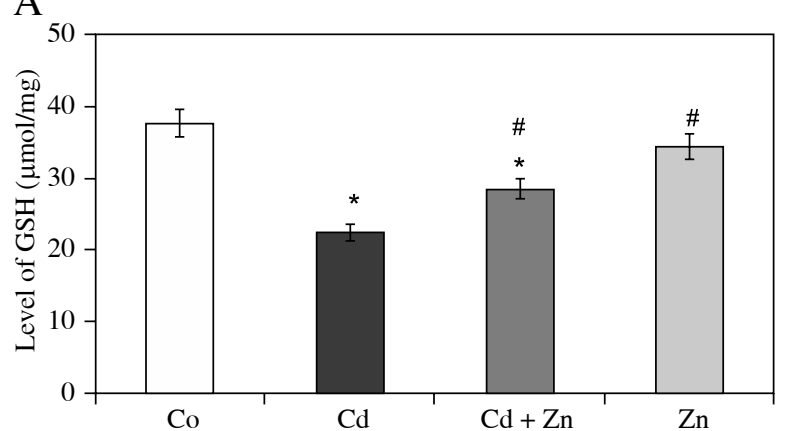

C

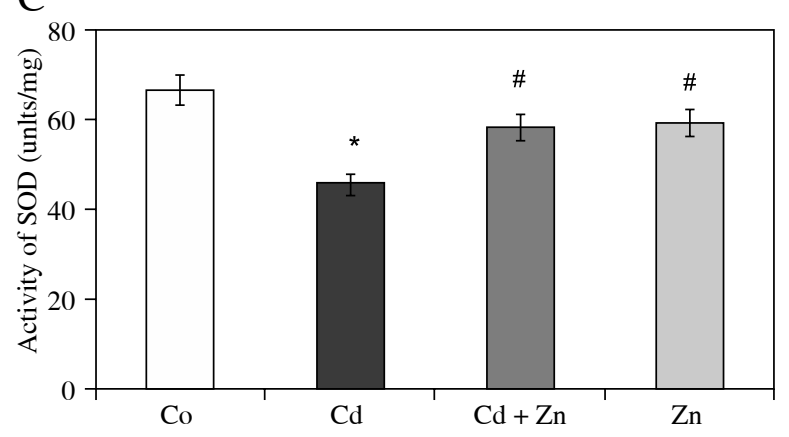

B

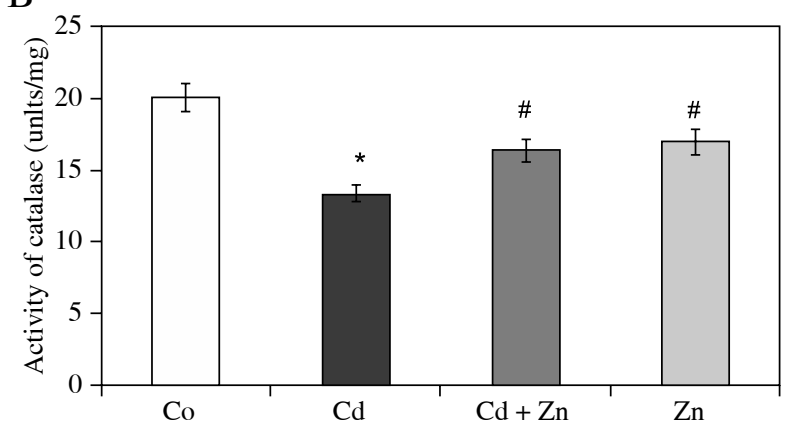

D

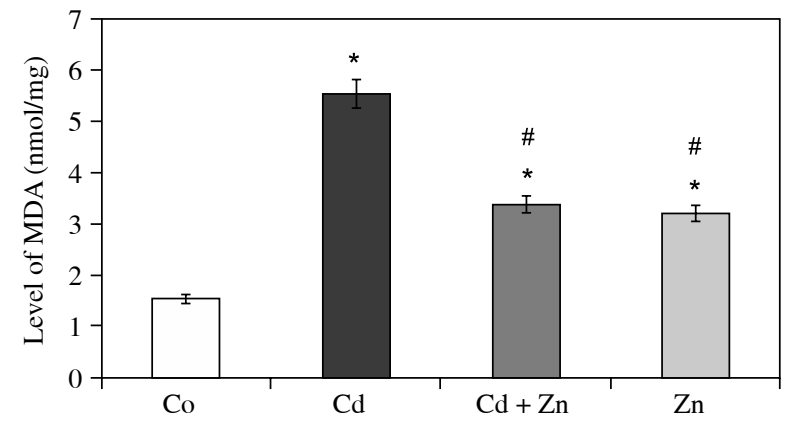

Fig. 1. Effect of the treatment on the level of reduced glutathione (GSH) (A), the major antioxidant enzymes CAT (B), SOD (C) and the level of lipid peroxidation (MDA) (D) in spleen samples. *shows the significance $(p<0.05)$ in comparison to the control group. "shows the significance $(p<0.05)$ in comparison to the Cd-treated group
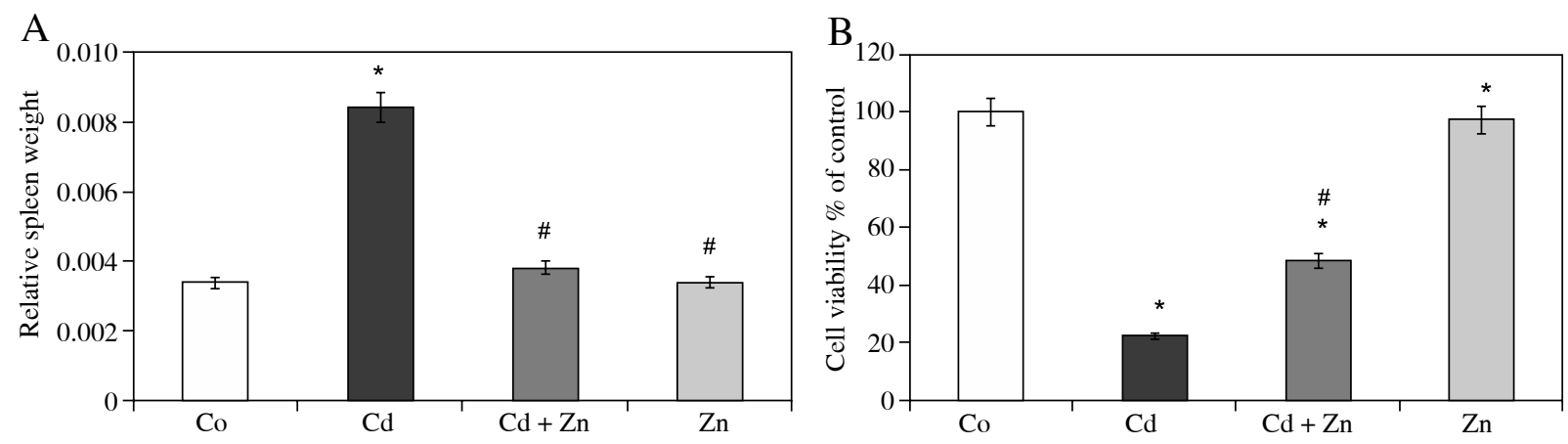

Fig. 2. A) Relative spleen weight from different groups showing the significant higher spleen relative weight of Cd rats in comparison to the control and other groups. Zn was found to significantly restore the spleen relative weight in Cd + Zn rats. B) MTT assay for the cell viability percentage of splenocytes from the four different groups. Values are the mean \pm SD. *shows the significance $(p<0.05)$ in comparison to the control group. " shows the significance $(p<0.05)$ in comparison to the Cd-treated group

\section{Effect on the level of lipid peroxidation}

Estimation of malondialdehyde (MDA) was carried out to assess the extent of lipid peroxidation in spleen samples after the treatment. Zinc demonstrated an increase in the MDA level by $43.8 \%$ in spleen whereas $\mathrm{Cd}$ showed the rise by $92.8 \%$ in the samples. In the combination group $(\mathrm{Cd}+$ $+\mathrm{Zn}$ ), its level decreased by $19 \%$ in spleen samples indicating the ameliorative effect of $\mathrm{Zn}$ on Cd-toxicity (Fig. 1D).

\section{Zinc protected spleen and splenocytes viability against Cadmium intoxication}

The relative weight of the spleen in animals from the Cd-treated group revealed that splenomegaly (Fig. 2A) was a clearly distinguishable feature compared to those from the control animals. Zinc was found to restore the relative weight of the spleen towards the normal in comparison with the control rats. To validate these observations as well 

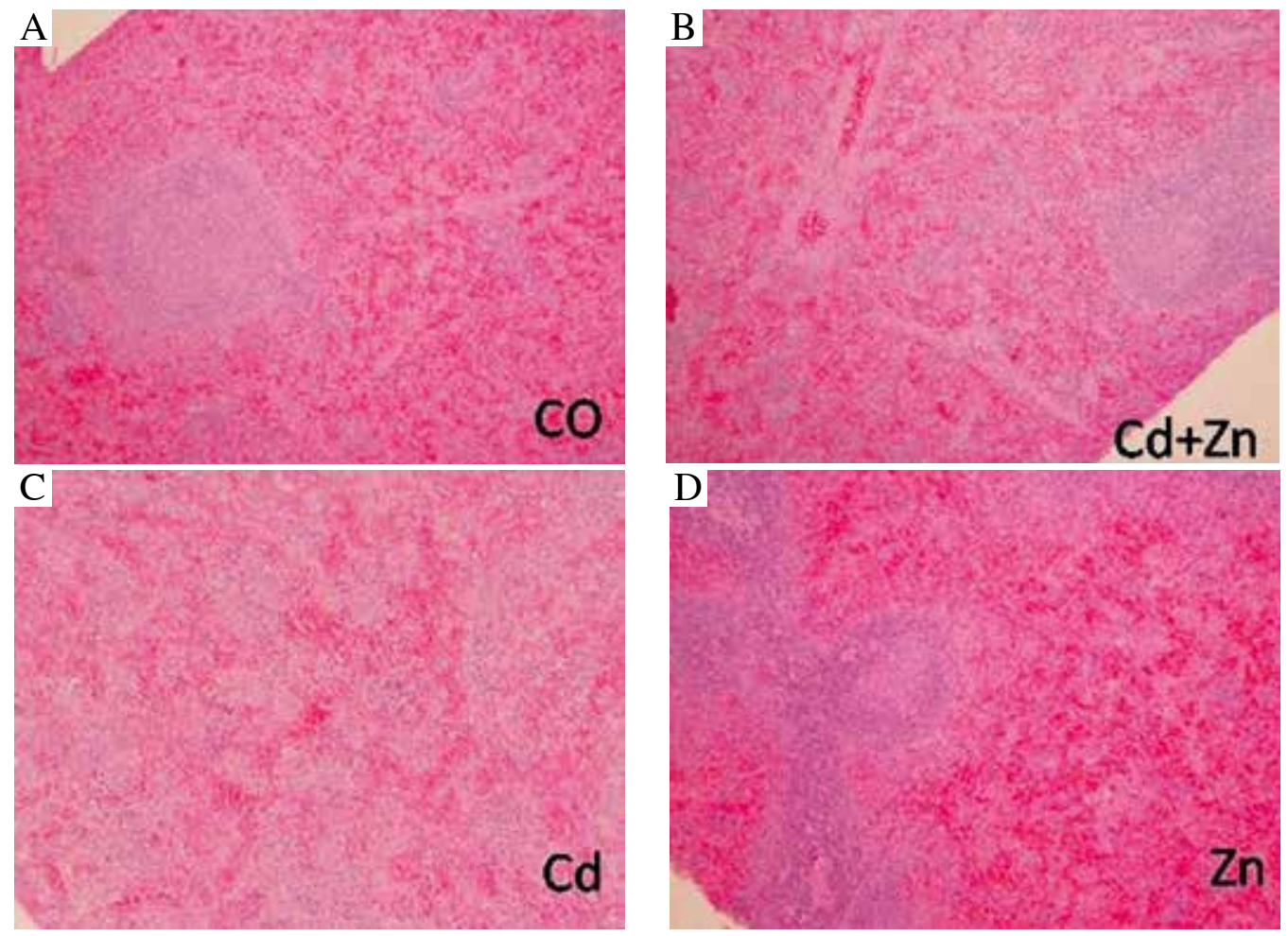

Fig. 3. Representative spleen sections stained with $\mathrm{H} \& \mathrm{E}$ from control (A) $\mathrm{Cd}+\mathrm{Zn}$ (B), (C), and Zn (D) groups (200x)
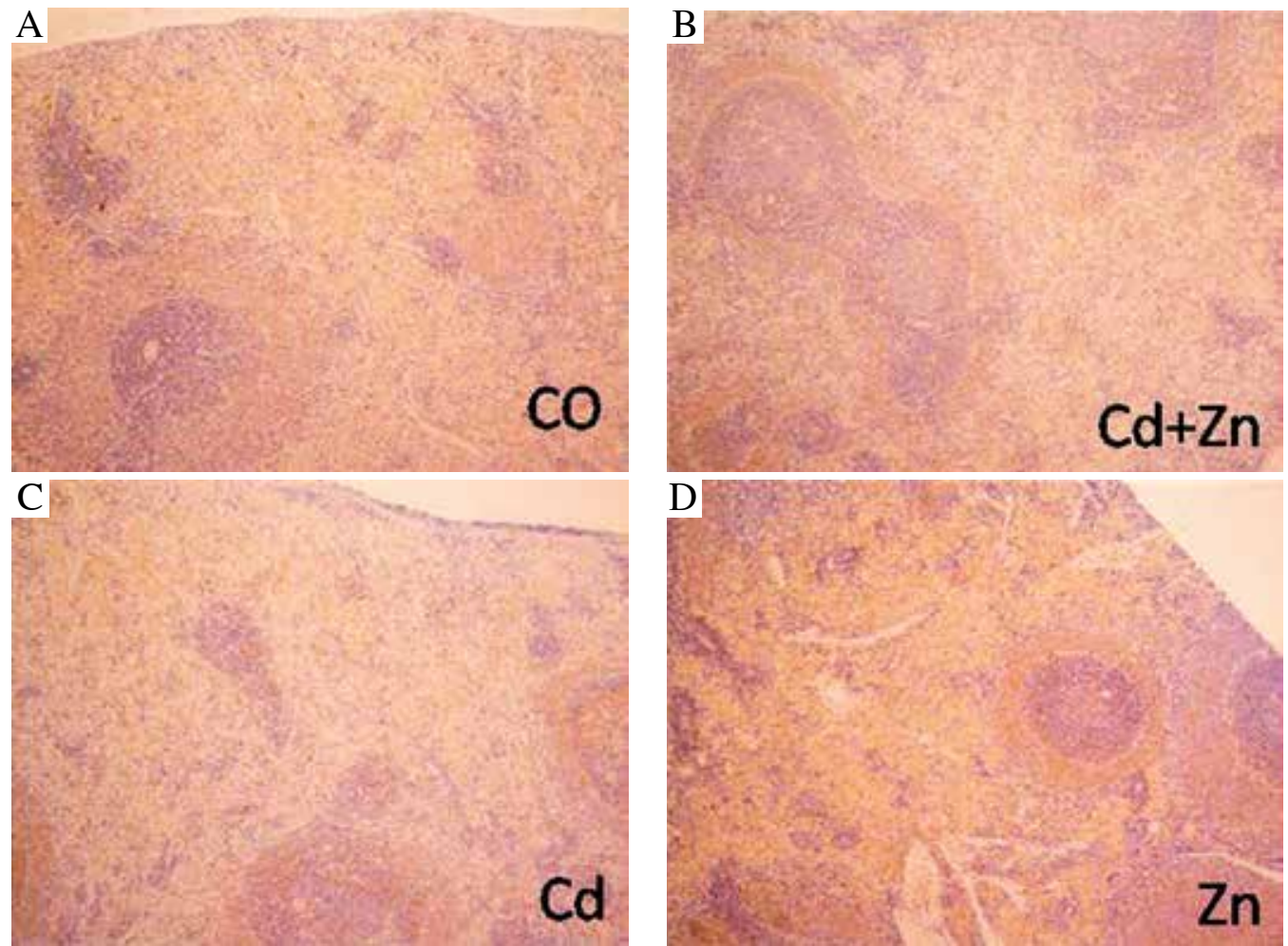

Fig. 4. Spleen sections stained with anti-CD3+ antibodies to realize $\mathrm{T}$ cells from control (A), $\mathrm{Cd}+\mathrm{Zn}(\mathrm{B}), \mathrm{Cd}(\mathrm{C})$ and $\mathrm{Zn}$ (D) groups (200x) 

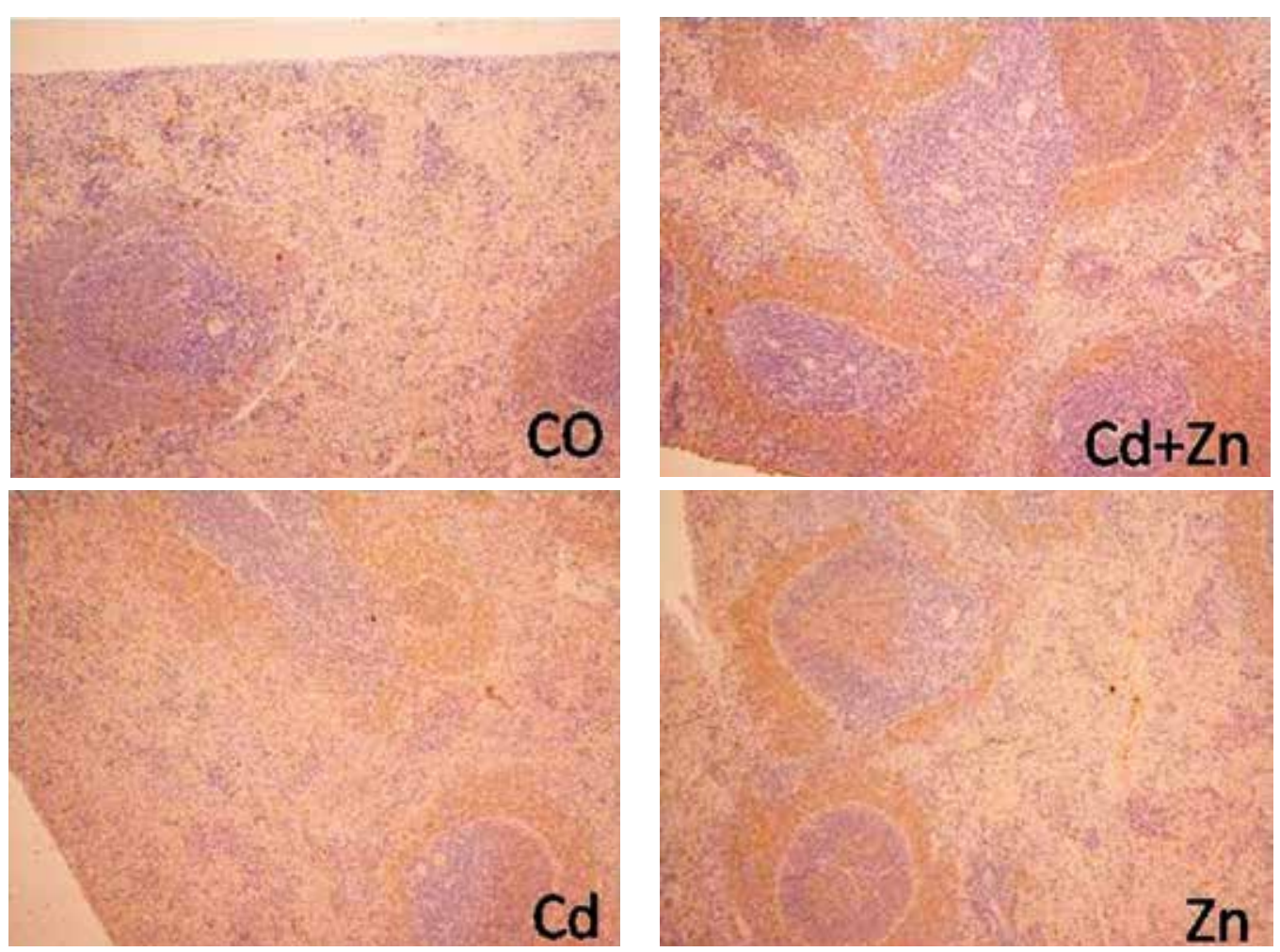

Fig. 5. Spleen sections stained with anti-CD20+ antibodies to realize B cells from control (A), Cd $+\mathrm{Zn}(\mathrm{B}), \mathrm{Cd}(\mathrm{C})$ and $\mathrm{Zn}(\mathrm{D})$ groups $(200 \times)$

as for determination of the effect of Zn on lymphocyte activities, lymphocytes from the Cd-treated rats and the other three groups were isolated and examined for cell proliferation. Viability of the lymphocytes was measured by the trypan blue exclusion test. Approximately $80 \%$ of lymphocytes of Cd-treated rats were killed in medium during 72 hours of incubation comparing to the control rats (Fig. 2B). Non-significant changes of the lymphocytes derived from $\mathrm{Zn}$-treated rats comparing to the control rats.

\section{Zinc improved spleen histological architecture}

Light microscopic examination of sections from the spleen of Cd-treated rats showed that the white pulp was extensively diffused while mature lymphocytes in peripheral sections of the spleen were also dramatically reduced (Fig. 3) in comparison with the control rats. Spleen sections from the combination groups $(\mathrm{Cd}+\mathrm{Zn})$ however showed an obvious improvement with normal distribution of lymphocyte population and normal ratio relative to the red pulp (Fig. 3).

\section{Zinc forced survival of $\mathbf{T}$ and B lymphocytes}

After MTT assay, we were interested to determine the extent to which both B and T cells were activated by Zn. Spleen sections were stained with anti-CD3 (Fig. 4) or anti-CD20 (Fig. 5) antibodies to realize T or B cells, respectively. T cells were extensively depleted in all splenic zones, especially in the PALS, in the spleen sections of the Cd-treated rats (Fig. 4) compared to the control group. Zinc was clearly found to restore these T cells quite comparable to their normal level. Furthermore, Figure 4 shows that the number of B cells was significantly $(p<0.05)$ reduced in both the marginal zone and lymphatic follicles of the Cd-treated rats compared to the control group. On the other hand, the number of B cells in the Cd-treated rats supplemented with $\mathrm{Zn}$ were significantly $(p<0.05)$ increased in both the marginal zone and lymphatic follicles compared to the Cd-treated and the control rats (Fig. 5).

\section{Effect of Zinc on the CXCL10 and $\mathrm{Ccl} 22$ chemokines, and a macrophage marker, CD68}

After observing improvement of $\mathrm{T}$ and $\mathrm{B}$ cell homing to spleen after $\mathrm{Zn}$ supplementation, the present study was aimed to test lymphocyte chemo-attractant chemokines. Chemokines are low molecular weight proteins involved in trafficking the inflammatory lymphocytes during pathogenesis. Results of the RT-PCR mRNA expression of the CXCL10 and Ccl22 chemokines, and CD68 confirmed that $\mathrm{Cd}$ was found to significantly elevate these genes in comparison to the control samples although $\mathrm{Zn}$ supplementa- 
A
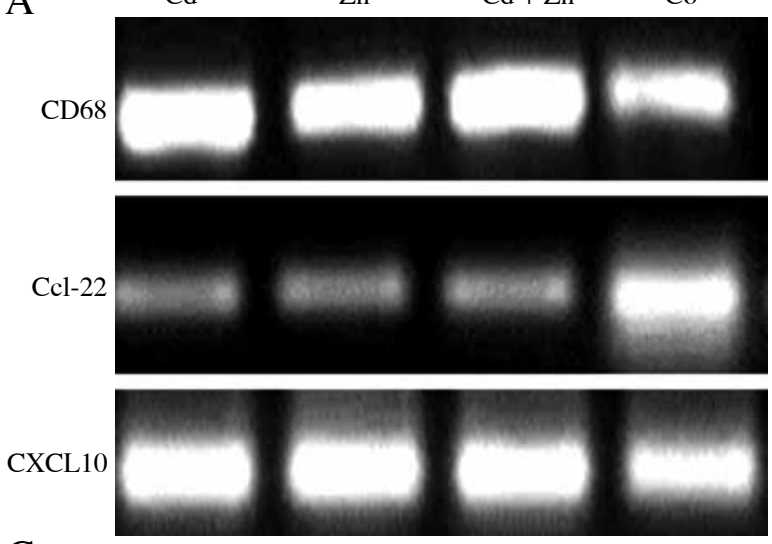

$\mathrm{C}$

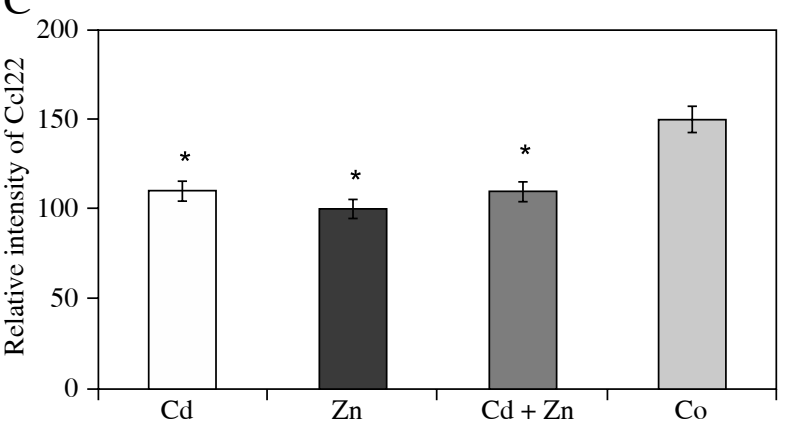

B

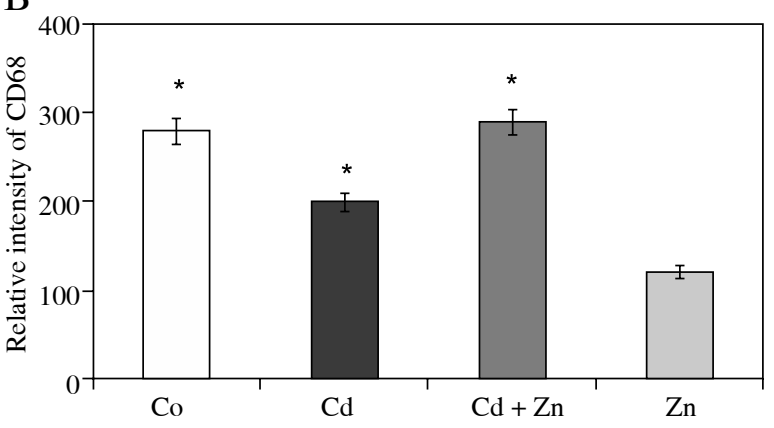

$\mathrm{D}$

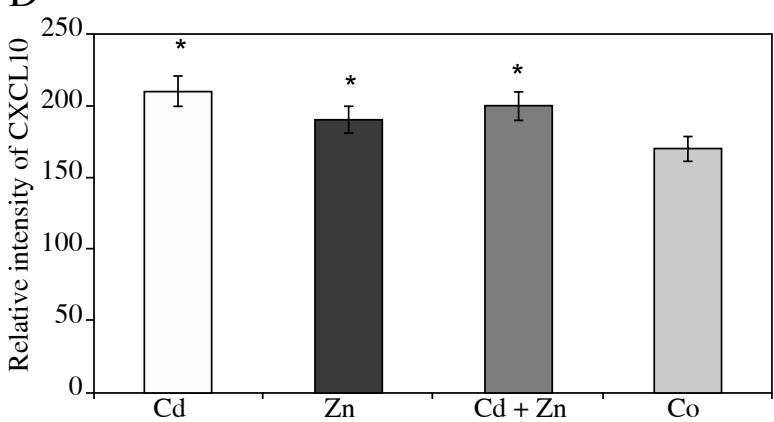

Fig. 6. RT-PCR mRNA expression of CD68, Cc122 and CXCL10 (A) of the antigen activated lymphocytes from different groups. B) The relative intensity of CD68 bands. C) The relative intensity of Ccl22 bands. D) The relative intensity of CXCL10 bands. PCR products were separated and visualized by DNA agarose electrophoresis after amplification of CD68, Ccl22 and CXCL10 from splenocyte genomic DNA. Values are the mean \pm SD. *shows the significance $(p<$ $0.05)$ in comparison to the control group $(\mathrm{Co})$. \#shows the significance $(p<0.05)$ in comparison to the Cd-treated group

tion could not restore mRNA expression of these genes to the normal levels after Cd damage (Fig. 6).

\section{Discussion}

Zinc is one of the most important minerals after iron and calcium in the living systems. Its moderate amount is essentially required in normal functioning of metabolism, defense and general well-being [7]. The current study is an attempt to exhibit the efficacy of $\mathrm{Zn}$ in restoration of immunity in Cd-pre-treated rats.

As Cd exerts its toxic insults in rats by oxidative stress [23], assessment of activity of major antioxidant enzymes (SOD, CAT, GSH) and extent of lipid peroxidation (MDA level) was carried out to confirm involvement of this stress in the present work. The results clearly demonstrate that Cd elicits its toxicity by disrupting the redox balance in rat spleen as the activity of SOD, CAT and GSH were much compromised concomitant with a highly elevated level of MDA in the Cd-treated group while the $\mathrm{Zn}$-treated group showed near control levels. Interestingly, the combination of $\mathrm{Cd}$ with $\mathrm{Zn}$ exhibited normalization of the activity of antioxidant enzymes and MDA levels that tended towards the control values significantly. Thus, this part of the study entails that there is a strong involvement of oxidative stress and $\mathrm{Cd}$ elicited free radical(s) damage that is significantly countered by Zn.

As $\mathrm{Zn}$ is an important component of CuZnSOD that plays an important role in activation of the enzyme, it is quite evident here that supplementation of $\mathrm{Zn}$ improved its activity that might act as an initiating contributor in restoration of the normal redox status in Cd-pre-treated rats [24]. In the same league, CAT and GSH might also assist to maintain the delicate balance of generation and quenching of damaging free radicals (superoxide anions, hydroxyl radicals). It might be the reason for a significant decrease in the MDA levels after treatment with $\mathrm{Zn}$ in the Cd-pre-treated group. These findings are also in agreement with earlier investigations that clearly showed that a supplementary diet of $\mathrm{Zn}$ in moderate amounts enhances gene expression of major antioxidant enzymes and protective proteins [10]. 
A depletion of lymphocytes, both $\mathrm{T}$ and $\mathrm{B}$, has been demonstrated by the histological and immunohistochemical staining of spleen sections from the Cd-treated group. In addition, the proliferation of lymphocytes was found to be suppressed in Cd-treated rats. On the other hand, $\mathrm{Zn}$ served to activate the proliferation of $\mathrm{B}$ and $\mathrm{T}$ lymphocytes in Cd-treated rats both in vivo and in vitro. Furthermore, the $\mathrm{T}$ and $\mathrm{B}$ cell homing to the spleen was clearly restored after $\mathrm{Zn}$ treatment.

Although CXCL10 and its receptor, CXCR3, appear to contribute to the pathogenesis of many autoimmune diseases, organ specific or systemic [15], CXCL10 may not interfere with the pathogenesis caused by Cd contamination. Although $\mathrm{Zn}$ supplementation improved the histological structure of spleen and the homing of $\mathrm{T}$ and $\mathrm{B}$ cells with restoration of oxidative stability in this organ, it could not restore mRNA expression of CXCL10, $\mathrm{Ccl} 22$, and CD68 to the normal levels after Cd impairment of these genes. This indicates that $\mathrm{Zn}$-induced improvement was not due to the suppression of these genes. It might be due to the oxidative stability and the suppression of its oxidative-related markers such as TNF-a and its receptors which play crucial roles in the pathogenesis of diseases since the prognosis of patients has improved by biologics targeting TNF- $\alpha$ and interleukin 6 [25].

The authors extend their appreciation to the Deanship of Scientific Research at King Saud University for funding the work through research group project No. RGPVPP-028.

The authors declare no conflict of interest.

\section{References}

1. Morrow H (2010): Cadmium and Cadmium Alloys. Kirk-Othmer Encyclopedia of Chemical Technology; 1-36.

2. Tabrez S, Priyadarshini M, Priyamvada S, et al. (2014): Gene-environment interactions in heavy metal and pesticide carcinogenesis. Mutat Res Genet Toxicol Environ Mutagen 760: 1-9.

3. De Silva PE, Donnan MB (1981): Chronic cadmium poisoning in a pigment manufacturing plant. $\mathrm{Br} \mathrm{J}$ Ind Med 38: 76-86.

4. Vergilio Cdos S, de Melo EJ (2013): Autophagy, apoptosis and organelle features during cell exposure to cadmium. Biocell 37: 45-54.

5. Chen DJ, Xu YM, Du JY, et al. (2014): Cadmium induces cytotoxicity in human bronchial epithelial cells through upregulation of eIF5A1 and NF-kappaB. Biochem Biophys Res Commun 445: 95-99.

6. Choong G, Liu Y, Templeton DM (2014): Interplay of calcium and cadmium in mediating cadmium toxicity. Chem Biol Interact 211: 54-65.

7. Shankar AH, Prasad AS (1998): Zinc and immune function: the biological basis of altered resistance to infection. Am J Clin Nutr 68: 447S-463S.
8. Lemire J, Mailloux R, Appanna VD (2008): Zinc toxicity alters mitochondrial metabolismand leads to decreased ATP production in hepatocytes. J Appl Toxicol 28: 175-182.

9. Fang YZ, Yang S, Wu G (2002): Free radicals, antioxidants, and nutrition. Nutrition 18: 872-879.

10. Wu C, Zhang W, Mai K, et al. (2011): Effects of dietary zinc on gene expression of antioxidant enzymes and heat shock proteins in hepatopancreas of abalone Haliotis discus hannai. Comp Biochem Physiol C Toxicol Pharmacol 154: 1-6.

11. Oteiza PI, Clegg MS, Zago MP, Keen CL (2000): Zinc deficiency induces oxidative stress and AP-1 activation in 3 T3 cells. Free Radic Biol Med 28: 1091-1099.

12. van den Borne P, Quax PH, Hoefer IE, Pasterkamp G (2014): The multifaceted functions of CXCL10 in cardiovascular disease. Biomed Res Int 2014: 893106.

13. Czaja AJ (2014): Review article: chemokines as orchestrators of autoimmune hepatitis and potential therapeutic targets. Aliment Pharmacol Ther 40: 261-279.

14. Schober A (2008): Chemokines in vascular dysfunction and remodeling. Arterioscler Thromb Vasc Biol 28: 1950-1959.

15. Antonelli A, Ferrari SM, Giuggioli D, et al. (2014): Chemokine (C-X-C motif) ligand (CXCL)10 in autoimmune diseases. Autoimmun Rev 13: 272-280.

16. Bayry J (2014): Regulatory T cells as adjuvant target for enhancing the viral disease vaccine efficacy. Virusdisease 25: 18-25.

17. Marklund S, Marklund G (1974): Involvement of superoxide anion radical in the auto oxidation of pyrogallol and a convenient assay for superoxide dismutase. Eur J Biochem 47: 469-474.

18. Aebi H (1984): Catalase in vitro. Methods Enzymol 105: 121-126.

19. Jollow DJ, Mitchell JR, Zampaglione N, Gillette JR (1974): Bromobenzene induced liver necrosis: protective role of glutathione and evidence for 3,4-bromobenzene oxide as hepatotoxic metabolite. Pharmacology 11: 151-169.

20. Buege JA, Aust SD (1978): Microsomal lipid peroxidation. Methods Enzymol 52: 302-310.

21. Ebaid H (2014): Promotion of immune and glycaemic functions in streptozotocin-induced diabetic rats treated with un-denatured camel milk whey proteins. Nutr Metab (Lond) 11: 31 .

22. Ebaid H (2014): Neutrophil depletion in the early inflammatory phase delayed cutaneous wound healing in older rats: improvements due to the use of un-denatured camel whey protein. Diagnostic Pathology 9: 46.

23. Xiong W, Sun Y, Zou M, Muhammad RU. Molecular cloning, characterization of CAT and eco-toxicological effects of dietary zinc oxide on antioxidant enzymes in Eiseniafetida. Environ Sci Polllut Res Int 20: 1746-1755.

24. Sidhu P, Garg ML, Dhawan DK (2005): Protective effects of zinc on oxidative stress enzymes in liver of protein-deficient rats. Drug Chem Toxicol 28: 211-230.

25. Inoue A, Matsumoto I, Tanaka Y, Sumida T (2012): Crucial role of TNF $\alpha$-induced adipose-related protein (TIARP) in the pathogenesis of autoimmune arthritis. Nihon Rinsho Meneki Gakkai Kaishi 35: 51-55. 